\title{
La "Notre Dame” española. La reconstrucción de la Catedral de Sigüenza tras la Guerra Civil
}

\author{
The Spanish "Notre Dame". The reconstruction of Sigüenza Cathedral after the \\ Spanish Civil War
}

\author{
$\underline{\text { Rocío Maira-Vidal }}^{(*)}$
}

\section{RESUMEN}

El año pasado el mundo observó incrédulo cómo las llamas devoraban en pocas horas una de las catedrales más relevantes de la Edad Media, Notre Dame de París. Sus bóvedas, una de las tipologías más interesantes y controvertidas del gótico primitivo, fueron el modelo a seguir en monasterios y catedrales de toda Europa. En España, la Catedral de Sigüenza es el único edificio que se construyó siguiendo el modelo exacto de los abovedamientos de la Catedral de París. Mientras que las bóvedas parisinas han sufrido importantes derrumbes en el incendio, las seguntinas fueron destruidas parcialmente en los bombardeos de la Guerra Civil. Este artículo analiza los procesos constructivos y los medios utilizados para llevar a cabo esta difícil reconstrucción en plena postguerra, delatando importantes diferencias respecto de las bóvedas originales, consecuencia de la falta de estudios previos. Además, se han conseguido determinar partes originales que hasta ahora se consideraban reconstruidas.

Palabras clave: Catedral de Sigüenza; reconstrucción; gótico; bóvedas; sexpartitas; Torres Balbás; Antonio Labrada; Notre Dame de París.

\section{ABSTRACT}

Last year the world was astonished to see how fire consumed one of the most relevant cathedrals of the Middle Ages in a few hours. Their vaults, one of the most interesting and controversial typologies of the Early Gothic, became the model followed by monasteries and cathedrals all over Europe. In Spain, Sigüenza Cathedral was the unique example built following the typology of Notre Dame de Paris vaults. While Parisian vaults have been seriously damaged by fire, the vaults of Sigüenza Cathedral had been partially destroyed by Spanish Civil War bombings. This paper analyses the construction processes and the resources used to carry out its difficult reconstruction during the postwar, pointing out important differences regarding the original vaults as the consequence of the lack of prior studies. In addition, it has been possible to define which of the vaults, considered so far as reconstructed structures, are truly original.

Keywords: Sigüenza Cathedral; reconstruction; Gothic; vaults; sexpartite; Torres Balbás; Antonio Labrada; Notre Dame de Paris.

(*) Doctora Arquitecta. Investigadora postdoctoral. Instituto de Historia. CCHS. CSIC, Madrid (España).

Persona de contacto/Corresponding author: rociomaira@enjarje.com (R. Maira-Vidal)

ORCID: https://orcid.org/oooo-0001-5408-0067 (R. Maira-Vidal).

Cómo citar este artículo/Citation: Rocío Maira-Vidal (2021). La "Notre Dame" española. La reconstrucción de la Catedral de Sigüenza tras la Guerra Civil. Informes de la Construcción, 73(563): e401. https://doi.org/10.3989/ic.80767

Copyright: (C) 2021 CSIC. Este es un artículo de acceso abierto distribuido bajo los términos de la licencia de uso y distribución Creative Commons Reconocimiento 4.0 Internacional (CC BY 4.0). 


\section{LA RELACIÓN DE NOTRE DAME DE PARÍS Y LA CATEDRAL DE SIGÜENZA}

Las bóvedas sexpartitas constituyen una de las tipologías más características del gótico temprano europeo. Estas estructuras son bóvedas de crucería con seis nevios: cuatro diagonales que confluyen en la clave y otros dos que dividen la bóveda en dos mitades simétricas, los llamados centrales o de través, y que añaden dos apoyos intermedios a los cuatro esquineros. Estos abovedamientos se utilizaron durante un breve periodo de tiempo, fundamentalmente entre los siglos XII y XIII, como consecuencia de las dificultades asociadas a su construcción (1).

Para llevar a cabo la construcción de las bóvedas góticas era necesario definir la curvatura de sus nervios previamente, que se llevaba a cabo en la sala de trazas o en otros espacios de la obra, incluso sobre los muros o los tablones de andamios. Para ello se realizaban las monteas, los dibujos a escala real de cada nervio, que permitían la comprobación de las piezas que se iban tallando sobre el dibujo, e incluso de las cimbras, las estructuras de madera encargadas de soportar su peso durante el montaje. Las bóvedas sexpartitas se clasifican en cuatro tipologías distintas dependiendo de la geometría de sus nervios. Las bóvedas de la Catedral de Notre Dame de París responden a un modelo muy característico, cuyos nervios centrales forman un semicírculo peraltado más de dos metros sobre la línea de cornisa de apoyo (2). Sus nervios diagonales forman también nervios semicirculares, de mayor tamaño y con sus centros a la altura de la línea de cornisa (figura 1). Este modelo se extendió especialmente en la zona central y oriental del antiguo Imperio Carolingio, donde las formas redondeadas de las cúpulas bizantinas aún contaban con una importante influencia en la arquitectura medieval. Sin embargo en la región de París no fueron tan frecuentes, y mucho menos en Gran Bretaña y España. En nuestro país la bóveda sexpartita se extendió en la mitad norte y central de la Península, pero solo la Catedral de Sigüenza siguió el modelo geométrico parisino, siendo un caso peculiar en Castilla.

La tipología de bóveda sexpartita que se utilizaba de forma más frecuente se diferencia del modelo parisino por la geometría de su nervio central, en este caso apuntado y ligeramente peraltado sobre la línea de imposta, del orden de 30 $\mathrm{cm}$. Las dos tipologías restantes son menos habituales, utilizándose únicamente en algunos casos en Gran Bretaña y España, y en ellas el cambio se produce en la geometría de los nervios diagonales, apuntados en una y rebajados en la otra, mientras que el resto de sus nervios son apuntados (2).
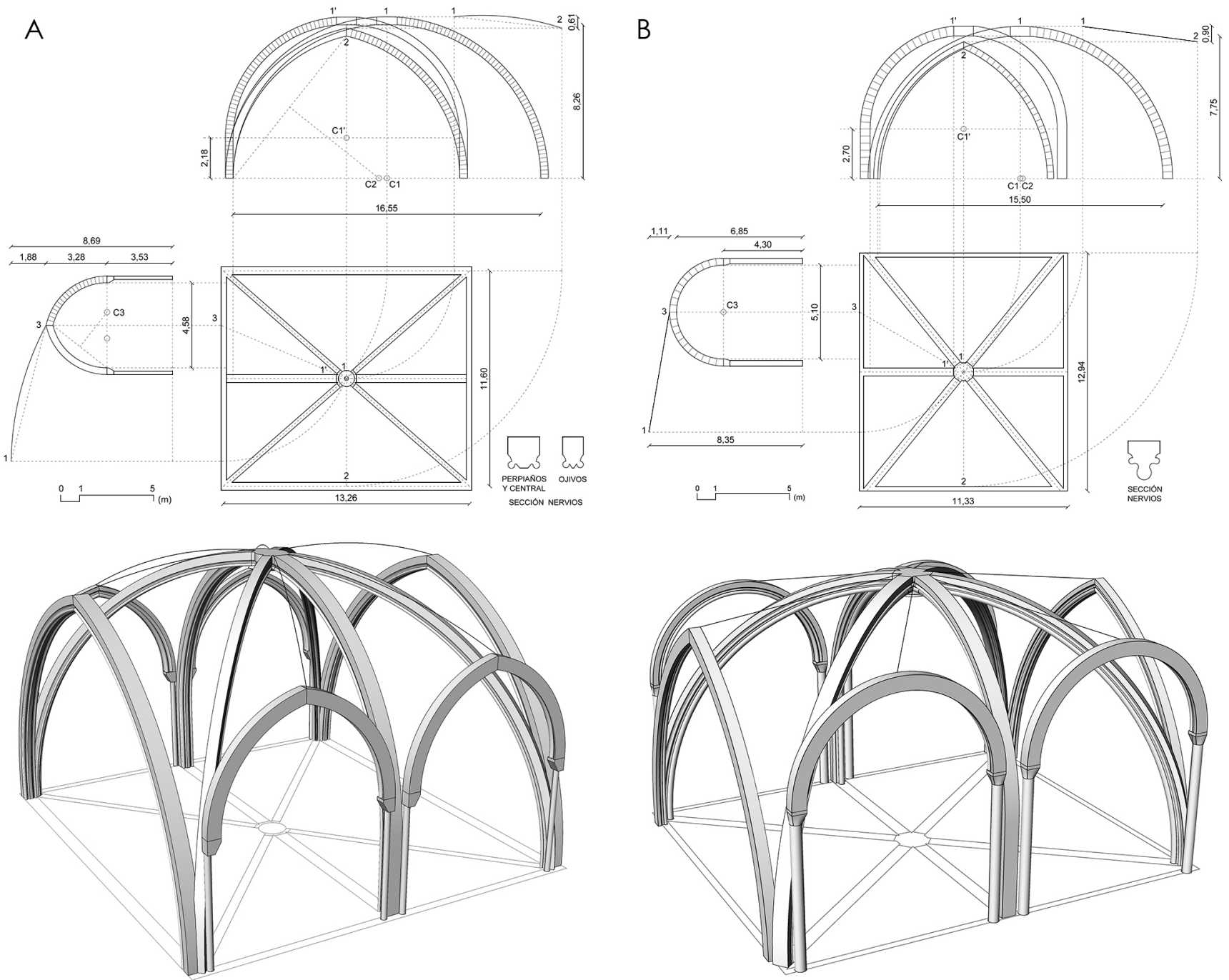

Figura 1. A: Montea y modelo 3D de las bóvedas sexpartitas de la Catedral de Notre Dame de París. B: Montea y modelo 3D de la bóveda sexpartita original del crucero sur de la Catedral de Sigüenza. Dibujos de la autora. 
Las bóvedas sexpartitas plantean importantes retos para llevar a cabo su construcción. Cuatro de los paños de plementería presentan formas abocinadas como consecuencia de los dos nervios centrales; se trata de superficies alabeadas de dificil definición y ejecución. Además sus apoyos esquineros son distintos de los centrales, porque reciben un mayor número de nervios, lo que complica las labores de talla de sus dovelas (figura 2). El modelo parisino presenta además diferencias significativas entre sus nervios diagonales y el central, como consecuencia del enorme peralte de éste último, lo que complica el diseño de las cimbras de madera, que apoyan a diferentes alturas sobre la plataforma de trabajo que debe montarse a la altura de la cornisa de apoyo.

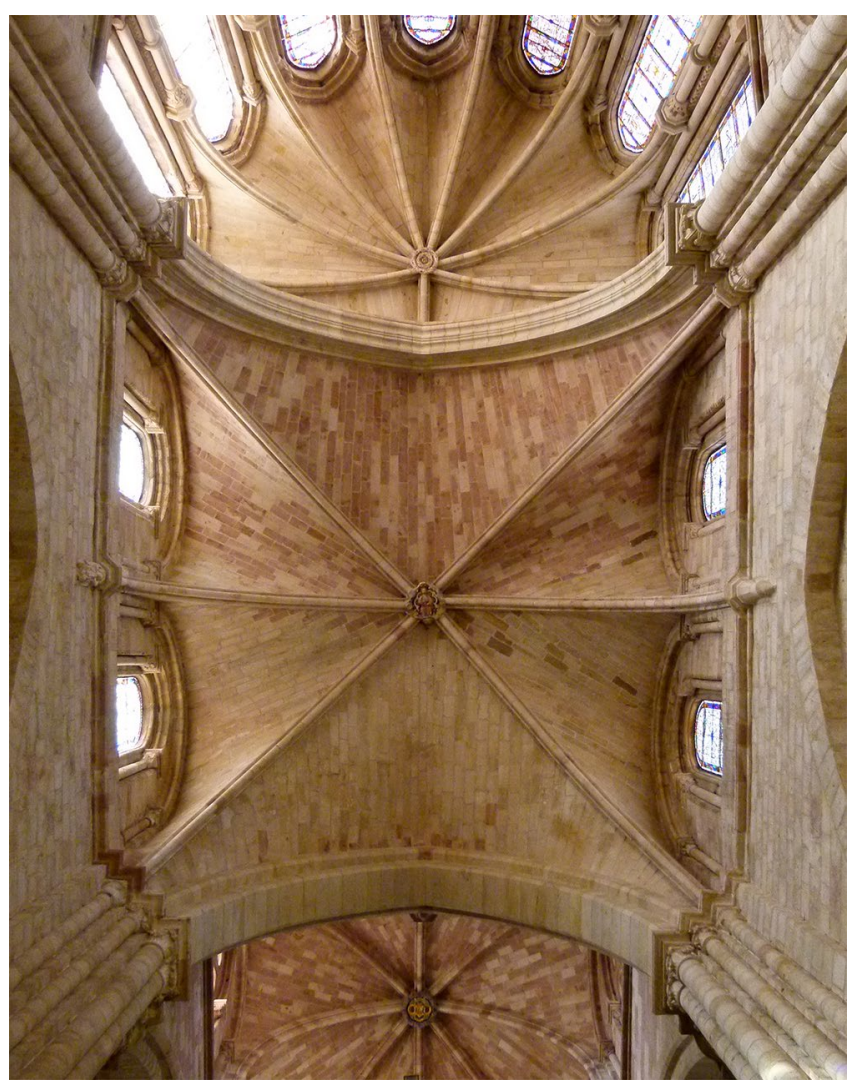

Figura 2. Bóveda sexpartita del presbiterio de la Catedral de Sigüenza. Fotografía de la autora.

Teniendo en cuenta estas características, la reconstrucción de las bóvedas de la Catedral de París será sin duda una empresa dificil y delicada. Los grandes estudios de arquitectura internacionales están planteando ideas vanguardistas para llevar a cabo la restauración de la catedral parisina. La mayor parte de las propuestas son descabelladas y no se basan en el profundo conocimiento del edificio y del funcionamiento de las estructuras medievales. Su objetivo es llamar la atención entre la larga lista de ideas propuestas, modificando drásticamente la estructura superior de la catedral para adaptarla a la estética y los materiales empleados en pleno siglo XXI. Habrá que confiar en el buen criterio de los organismos públicos encargados de velar por el patrimonio histórico francés. La estructura de madera de la cubierta plantea importantes problemas en su reconstrucción por haberse perdido en su totalidad, sin embargo sus bóvedas sólo han quedado afectadas parcialmente por el incendio, lo que requiere su restauración utilizando los materiales y la forma originales, siguiendo los principios de la construcción medieval. Las bóvedas que aún permanecen en pie, así como los pormenorizados levantamientos y estudios sobre su estructura previos al incendio (3), permitirán llevar a cabo estos trabajos con precisión.

La reconstrucción de las bóvedas de la Catedral de Sigüenza planteó los mismos problemas estructurales y constructivos a los que se enfrenta ahora el equipo de arquitectos restauradores franceses. Una retrospectiva de estos trabajos nos permite comprobar los medios humanos y materiales necesarios para llevarlos a cabo. Su reconstrucción se realizó de forma satisfactoria, especialmente teniendo en cuenta las carencias propias del momento histórico y la dificultad de construir la bóveda sexpartita de mayor altura de nuestro país, con 27 metros en su clave, y que cubre la mayor luz entre apoyos, nada menos que 11 metros. Sin embargo su estudio pormenorizando también revela discordancias frente a las bóvedas originales, derivadas de la falta de estudios previos y de la carencia de conocimientos en construcción medieval. Merece la pena llamar la atención sobre estos detalles, especialmente ahora que se presenta una situación similar.

\section{LA RECONSTRUCCIÓN DE LA CATEDRAL DE SI- GÜENZA}

La reconstrucción de Sigüenza comenzó en plena Guerra Civil, en 1937, y contó con pocos medios, además de la dificultad de encontrarse muy próxima al frente de batalla. Estos trabajos se prolongaron después de 1939. En plena postguerra no había personal cualificado disponible, por lo que la ejecución de las cimbras necesarias para las bóvedas, los trabajos de talla y el montaje de las piezas resultaron muy complicados, sin embargo el delicado estado de la catedral requería una rápida respuesta. Los estudios previos necesarios para acometer la reconstrución no se llevaron a cabo, provocando importantes desacuerdos entre las bóvedas originales y las reconstruidas. El arquitecto encargado de la restauración, Leopoldo Torres Balbás, fue apartado de la obra en 1940 por motivos políticos, dejando a cargo a su aprendiz Antonio Labrada, un arquitecto joven con poca experiencia (4). Algunas zonas de las bóvedas, prácticamente suspendidas en el aire desafiando las leyes de la gravedad, amenazaban ruina inminente y planteaban la importante tarea de valorar su estado para decidir si se demolían o conservaban. En los informes técnicos y los proyectos de restauración conservados se detalla el estado de ruina y se plantean las actividades previstas, sin embargo la falta de informes finales una vez terminada la obra no permite conocer si las zonas más comprometidas fueron demolidas y reconstruidas en su totalidad o simplemente consolidadas. El análisis que he realizado permite confirmar cuáles fueron los criterios de restauración empleados finalmente. En contraposición a las tesis apoyadas hasta ahora por otros investigadores, este estudio permite confirmar que la mitad de la bóveda del presbiterio es original.

\section{DAÑOS EN LAS BÓVEDAS DURANTE LA GUE- RRA CIVIL}

La Guerra Civil española trajo consigo la destrucción parcial de la cabecera y crucero de la Catedral de Sigüenza con el hundimiento de la bóveda sexpartita del brazo crucero norte y parte de la sexpartita del presbiterio, además de la bóveda semicircular del ábside y la cuatripartita del crucero central. Los abovedamientos de la nave solo sufrieron perforaciones locales en sus superficies de plementería. 
El arquitecto a cargo de su restauración durante la guerra Leopoldo Torres Balbás, llevó a cabo los primeros trabajos de reparación y definió con precisión los daños sufridos en la fábrica. En un primer informe en 1937 describió su estado de deterioro después de la Batalla de Sigüenza (agosto-octubre de 1936): fundamentalmente presentaba derrumbes parciales en los muros y bóvedas de la nave, la destrucción de la parte alta de la torre situada en la esquina sureste del crucero meridional, y la cubierta sobre la bóveda de este brazo del crucero (5).

En enero de 1938, mientras se estaba trabajando en su restauración, un aeroplano de la República dejó caer algunas bombas, provocando el derrumbe de parte de la bóveda del crucero norte y sus muros (figura 3). La ruina parcial de este abovedamiento,donde la esquina noroeste de sus plementerías permanecía en pie a pesar de haber perdido el nervio diagonal sobre el que se apoyaba, puso nuevamente de manifiesto la capacidad autoportante de estas superficies, que resultaban ser perfectamente estables aún habiendo perdido los nervios de apoyo, tal y como defendían Pol Abraham y Torres Balbás (67) en contraposición a las teorías decimonónicas de Viollet Le Duc (8). El funcionamiento estructural de estos elementos ya había quedado en evidencia después de los daños producidos por los bombardeos de la I Guerra Mundial sobre las catedrales francesas de Soissons y Rheims (9).

Entre 1937 y 1940 Torres Balbás llevó a cabo las labores de restauración de las partes dañadas en función de la urgencia de su estado de ruina. Los primeros trabajos se centraron en los muros y contrafuertes de la nave y en el crucero sur. La falta de mano de obra especializada y la economía obligó a dejar las piezas repuestas como sólidos capaces, sin decora- ción, para que fueran esculpidas en el futuro cuando se contase con buenos canteros. Los cuatro tramos de las bóvedas de la nave presentaban ocho perforaciones en su plementerías, que fueron reparadas colocando las piezas que faltaban. Posteriormente se desyagó su tradós y se reforzó con una capa de cemento, sobre la que apoyarían los nuevos tabiquillos de rasilla de las cubiertas. La bóveda sexpartita del crucero sur, la única del transepto que se conservó completamente original, requirió la reparación de su cubierta, destruida por los cañonazos recibidos y por la caída sobre ella de la parte alta de la torrecilla del Santísimo. Se desescombró el extradós de la bóveda, se desyagó y se reforzó con una capa de cemento sobre la que se construyó la cubierta siguiendo el mismo sistema que en la nave central.

$\mathrm{Al}$ final de la guerra la cabecera resultó de nuevo seriamente dañada, perdiéndose las bóvedas del ábside y del crucero norte y central en su totalidad, así como la mitad oriental del presbiterio (figura 3).

En 1940 Balbás redactó el proyecto de restauración de la catedral que contemplaba la reconstrucción de las bóvedas de la cabecera, la parte perdida de sus muros de apoyo, y dos de los arcos torales del crucero (5). Sin embargo don Leopoldo fue apartado de la obra poco después de la redacción de este proyecto, siendo sustituido por Antonio Labrada, que entregó un informe en diciembre de 1940 describiendo el estado del edificio y el plan de obras a realizar (10): "Hállanse derrumbadas desde sus arranques las bóvedas que cubren los tramos central y N. del crucero. En igual estado se encuentran las del presbiterio y el ábside." Esta información previa contradecía los planos y el proyecto de Torres Balbás, sin embargo después matizaba: "La boveda que cubre el presbiterio, conserva enteros tres de
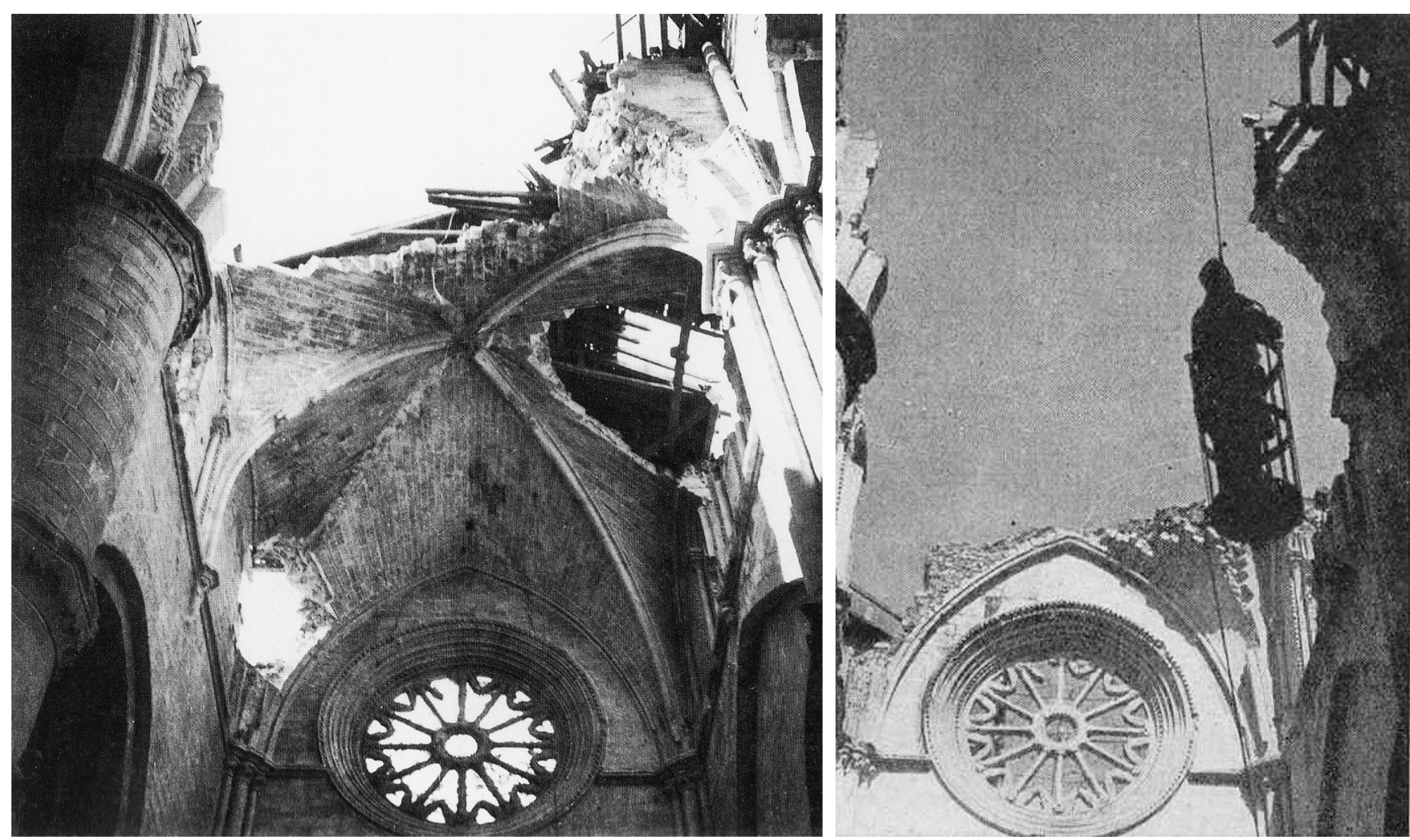

Figura 3. A la izquierda, estado de la bóveda del crucero norte como consecuencia del bombardeo de 1938. Fotografía de Torres Balbás (19). A la derecha, ruina total de la bóveda del crucero norte al final de la contienda. Fotografía de Antonio Labrada (13). 

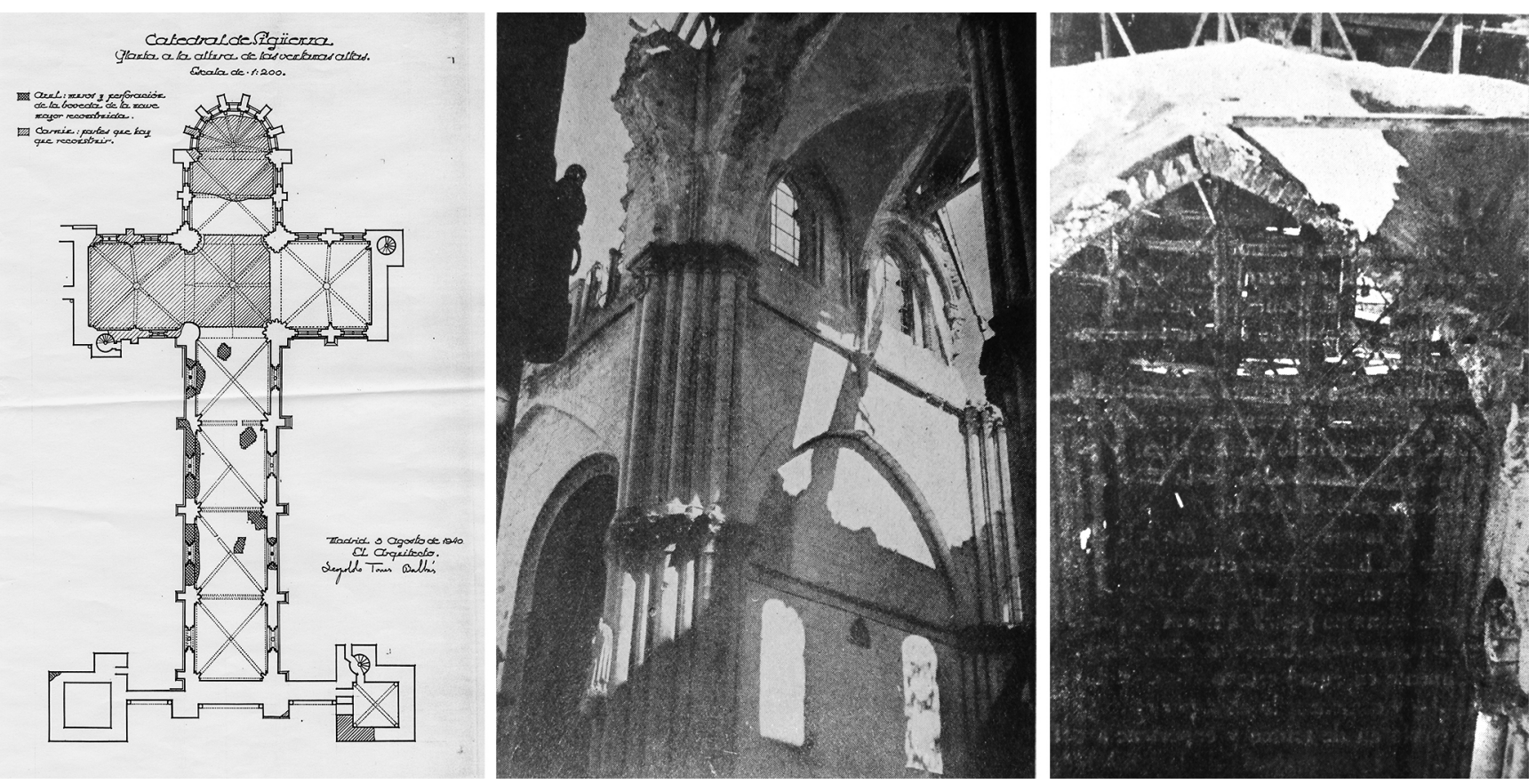

Figura 4. Plano indicativo de los daños en la catedral realizado por Torres Balbás para el proyecto de restauración de 1940 (izquierda). Estado de ruina de la bóveda del presbiterio al final de la guerra (centro y derecha). Fotografías de Antonio Labrada (13).

sus paños, aunque habrá que efectuar reparaciones en la plementería. El resto se halla hundido, como asimismo todos sus nervios, de los que existen restos que permiten reconstruirlos con su antiguo perfil. Por suerte se conserva también la clave -magnifico ejemplar- que aunque algo deteriorada conserva incluso los enjarjes de los nervios.” Esta descripción detallada confirma que la mitad Oeste de la bóveda se mantenía en pie, no sus nervaduras pero sí sus superficies de plementería, información que se puede verificar con las fotografías conservadas (11) y el plano de Torres Balbás (12) (figura 4). En la descripción afirmaba también que era necesario rehacer el arco perpiaño que separa esta bóveda de la del ábside.

En la bóveda norte del crucero Labrada confirmó que se conservaban tanto la clave como algunas dovelas de los arranques de la bóveda, tal y como atestiguan algunas fotografías (13), que servirían de modelo para tallar las nuevas.

Para rehacer la bóveda del crucero central era necesario reconstruir los perpiaños oriental y septentrional, que la separan del presbiterio y del crucero norte. La bóveda se rehizo nueva por completo, siguiendo el modelo del crucero de la Catedral de Laon, con una linterna que iluminaba el espacio, completamente diferente a la estructura original que se había derrumbado.

\section{MEDIOS UTILIZADOS EN LA RECONSTRUCCIÓN}

Una de las partes más complicadas de llevar a cabo en las obras fueron las cimbras por su elevado coste, por lo que su uso se evitó en algunos casos, como en la restauración de las bóvedas de la nave, al tratarse de reparaciones parciales (5). Estos cuatro tramos abovedados, con 25 metros de altura, presentaban perforaciones en sus plementerías, la mayor de ellas de $4 \mathrm{~m}^{2}$ de extensión. Su reparación se realizó colocando los plementos arriostrados desde el trasdós de las bóvedas con ayuda de un operario colgado de una jaula. Un método similar, colocando las dovelas atadas con cuerdas y pesos

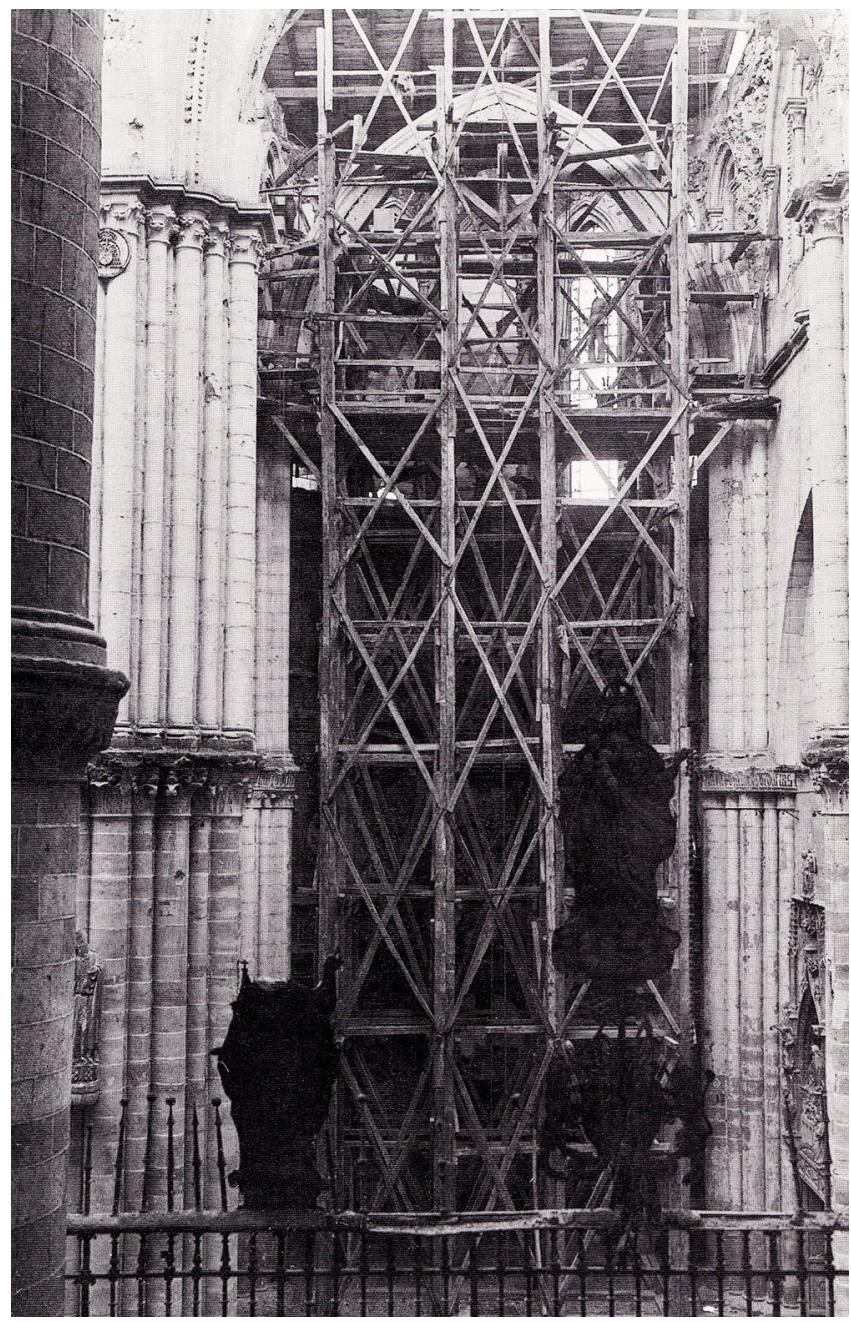

Figura 5. Castillete y cimbras de madera empleados en la reconstrucción de la cabecera. Fotografía de Antonio Labrada (13). 
desde el extradós, fue propuesto posteriormente por John Fitchen como posible sistema de ejecución de las plementerías en la Edad Media para abaratar los medios auxiliares, sin embargo esta hipótesis parece poco probable si se tienen que construir las superficies completas (14). Torres Balbás aconsejó este método por tratarse de reparaciones puntuales, de escasa extensión superficial, pudiendo apoyar las nuevas piezas en la parte de la plementería que aún se mantenía en pie.

En la reconstrucción de las bóvedas de la cabecera se optó por el montaje de grandes cimbras únicamente para los nervios, situadas entre los 18 y 26 metros de altura sobre el suelo del templo. Antes de abordar estos trabajos se llevaron a cabo las cimbras de los nervios torales, apeadas desde el suelo de la catedral. Balbás afirmó en su proyecto que las plementerías de las bóvedas de la cabecera se podrían ejecutar sin medios auxiliares que descansasen en el suelo, apoyando entre los nervios ojivos y perpiaños (5). Los plementos tendrían como máximo $20 \mathrm{~cm}$ de canto, según el arquitecto para facilitar la construcción, reducir el coste y disminuir los empujes de la estructura.

Labrada planteó en su informe la dificultad de llevar a cabo los medios auxiliares para reconstruir las bóvedas, no solo por su elevado coste, sino también por la escasez de mano de obra especializada (10). La madera era tan escasa y encarecía tanto la construcción que para los andamios de muros y torres se reutilizaron los pares y vigas de madera de las cubiertas originales desmontadas.

La línea de cornisa, que señala la cota a la que se debía de colocar la plataforma de apoyo para las cimbras de los nervios, se sitúa a 20 metros. En vez de construir castilletes y andamios de madera desde el suelo del templo para dar apoyo a las cimbras, el arquitecto propuso la construcción de varios castilletes metálicos con ruedas, de tal forma que una vez terminada una bóveda, los medios auxiliares se pudiesen reaprovechar en la siguiente, abaratando la obra y reduciendo los tiempos de ejecución. Estos planteamientos recuerdan los sistemas de estandarización de las bóvedas medievales, donde los nervios de los distintos tramos de abovedamiento se diseñaban con la misma curvatura para poder reutilizar las cimbras en los tramos siguientes, reduciendo los medios auxiliares al poder trasladarlos para ejecutar las nuevas bóvedas. Sin embargo este tipo de recursos no fueron empleados en la catedral seguntina, tal y como veremos más adelante, limitándose a reaprovechar los castilletes, pero no las cimbras. En las fotografías de la obra (13) podemos constatar que al menos los castilletes empleados para el apoyo de las cimbras de la cabecera, eran de madera y sin ruedas (figura 5).

En la fotografía de Archilla Salido del proceso de construcción de la bóveda del ábside se pueden ver las cimbras realizadas para el montaje de los nervios, con pequeños listones de madera clavados cada 40 o $50 \mathrm{~cm}$ en sus laterales, impidiendo así los movimientos de las dovelas fuera de su plano vertical durante su colocación (11). Los pies derechos y arriostramientos de la zona central permitían la colocación de tablones formando pequeñas plataformas de trabajo que se irían moviendo dependiendo del desarrollo de las obras. En la zona izquierda, a continuación de la última hilada de plementería ya terminada, hay una viga de madera apoyada sobre los castilletes auxiliares. Éste debió ser el tipo de apoyo empleado para la ejecución de las plementerías, que marcaba la dirección de la hilada y a su vez permitía apoyar los plementos hasta que la hilada se cerraba y los morteros de cal fraguaban ligeramente, pudiendo ser autoportante (figura 6). Este sistema tan sencillo evitó la fabricación de grandes cimbras para las plementerías y probablemente se asemeja a los métodos utilizados en la Edad Media (15).

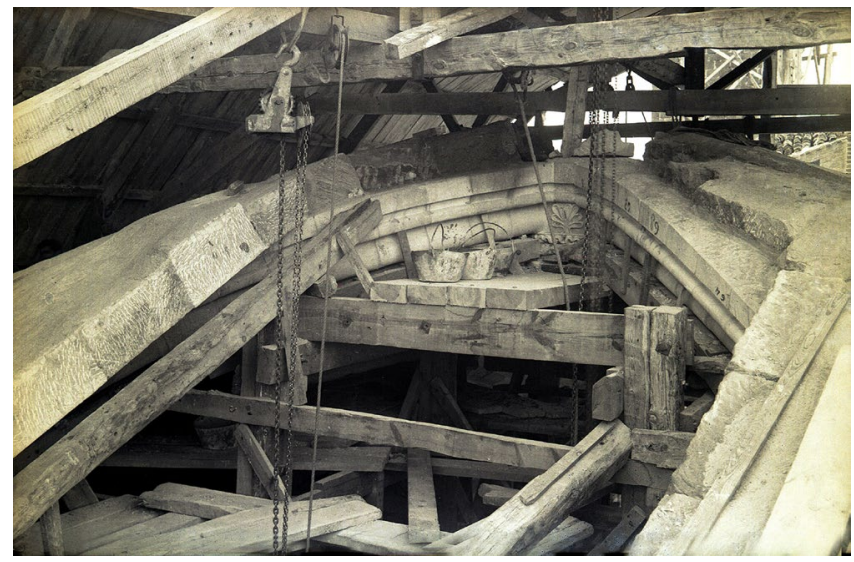

Figura 6. Cimbra ejecutada para el montaje de la bóveda del ábside. Fotografía de Pedro Archilla Salido (11).

Los trabajadores que colaboraron en las primeras obras, antes de 1940 y dirigidas por Torres Balbás, procedían de la localidad y contaban con conocimientos previos en albañilería: albañiles, mamposteros y canteros. El único operario foráneo era el encargado de la obra (5). Sin embargo para la reconstrucción de las bóvedas de la cabecera, Balbás preveía un mayor gasto en operarios al ser imprescindible una mayor cantidad de personal cualificado, dada la dificultad de los trabajos. La mayor especialización de la mano de obra no era necesaria para el montaje de las bóvedas, los muros o los arcos de apoyo, sino para realizar las labores de talla de las dovelas, arcos y ventanales, así como para la ejecucion de las cimbras. Ambos trabajos eran muy delicados y requerían la participación de personal con conocimientos específicos, inexistente en la localidad. Labrada también consideraba que los trabajos de mayor importancia, en cantidad y calidad, eran aquellos relacionados con la cantería. En su informe proponía la participación de los trabajadores empleados en ese momento en la reconstrucción del ferrocarril, prisioneros de guerra, para realizar el trabajo en la cantera, organizados bajo el mando de un capataz de la localidad conocedor de la cantera. Este tipo de mano de obra permitiría reducir los costes de la obra (10). Labrada señaló el problema de escasez de mano de obra especializada, necesaria para verificar la labra de los sillares a pie de obra. Solo había 6 canteros en la localidad, aunque el arquitecto suponía que el comienzo de los trabajos atraería a otros de la región, mientras que al resto habría que traerlos desde otras zonas de España. Ya en los años 40 las técnicas tradicionales estaban en declive: “..., con el deseo de que su terminación contribuya a restaurar una técnica constructiva casi olvidada,..." Labrada confirmó que se realizarían plantas, secciones, detalles y alzados para desarrollar el trabajo de cantería, que requeriría la elaboracion de plantillas a escala natural para relizar la talla de las piezas, tal y como se hacía en la Edad Media (16).

Las canteras se situaban a $1 \mathrm{Km}$ de la localidad, aunque parte de los caminos estaban en mal estado, lo que sin duda debió de complicar y retrasar el transporte de la piedra. 
Los nervios de las bóvedas se rehicieron aprovechando las dovelas que quedaron en buen estado después del derrumbe, así como dos de las claves, las de las bóvedas sexpartitas. Sin embargo buena parte de las piezas tuvieron que ser talladas de nuevo reproduciendo el perfil de las conservadas. Aquellas dovelas de las que no se conservaba ninguna pieza original, se tallaron sin molduras, al no disponer de la información necesaria para poder reproducirse.

En 1943 Labrada redacta un nuevo proyecto para la segunda fase de la restauración de la catedral donde añade una descripción de los trabajos ya ejecutados, entre los que se encuentran la reconstrucción de todas las bóvedas de la cabecera, a excepción del crucero central, que se encontraba a mitad del proceso (17). Los detalles del presupuesto permiten comprobar que las actividades más caras, además de los andamios, son los rejuntados, la extracción de la cantera, las ejecución de las bóvedas y la talla de sillería.

Una de las decisiones tomadas en obra, no prevista en el proyecto, fue la realización de la decoración en los elementos repuestos en la obra, lo que requirió la contratación de escultores y yesistas para hacer los modelos previos a la talla, que aumentaron notablemente el presupuesto inicial.

En este nuevo proyecto se preveía la reconstrucción tanto del perpiaño como de dos de los nervios de la bóveda de la nave situada sobre el coro, es decir, el primer tramo desde el crucero. Para ello se previó diponer también de cimbras apoyadas en medios auxiliares que se levantarían desde el suelo del templo.

\section{DETERMINACIÓN DE LAS BÓVEDAS ORIGINA- LES Y LAS RECONSTRUIDAS}

Torres Balbás planteó en principio el desmontaje de las partes ruinosas de las bóvedas que habían quedado en pie:

"En casi todos los muros y bóvedas que deben reconstruirse habrá que desmontar previamente las partes que están ruinosas por efecto de los obuses. En algunos lugares se halla la sillería completamente pulverizada. Así: en la torre Sur de la fachada, en la torre del Santísimo, en el brazo norte del crucero y en el ábside. En el presbiterio, o sea en el tramo que precede al ábside, se conserva una parte de la bóveda que lo cubría, aunque caídos sus arcos ojivos; parte de ella deberá derribarse por su estado ruinoso; si fuera posible, se aprovecharía el resto.” (5).

A partir de estas afirmaciones se podría considerar que la bóveda del ábside fue completamente reconstruída, desmontando previamente los tres paños de plementería suspendidos en el aire, puesto que amenazaban ruina.

Entre 1941 y 1942 Antonio Labrada realizó la reconstrucción del ábside, quedando pendientes las bóvedas del presbiterio y crucero. En abril de 1942, en la revista Reconstrucción, publicada por la Dirección General de Regiones Devastadas y Reparaciones, el arquitecto publica un pequeño artículo donde aparece una fotografía de la bóveda del presbiterio, aún en ruinas con sus tres cuarteles de plementería occidentales en pie (18). La leyenda de la fotografía afirma "plementería consolidada en el presbiterio", de donde se puede deducir que la intención del arquitecto es mantener esta mitad y reconstruir la mitad oriental desparecida. Sin embargo no se puede con- firmar esta información, porque en el siguiente informe, que data de 1943, Labrada no hizo referencia a las actividades ya terminadas, ni especificó con detalle las partidas de la obra ejecutadas (17). A pesar de que los indicios sugieren que la parte occidental de esa bóveda es original, los investigadores posteriores, como Juste Ballesta (19) y Muñóz Párraga (20), consideran que esta bóveda fue reconstruida en su totalidad.

Para llevar a cabo el análisis constructivo de las bóvedas sexpartitas de la Catedral de Sigüenza para mi tesis doctoral realicé un levantamiento pormenorizado de la cabecera con estación total láser, definiendo el despiece completo de sus bóvedas (figura 7). El trabajo de campo se alargó durante 17 días, lo que me permitió analizar in situ las bóvedas pieza por pieza (21). El visor de la estación total, con 42 aumentos, hizo posible la observación de las dovelas y plementos con detalle.

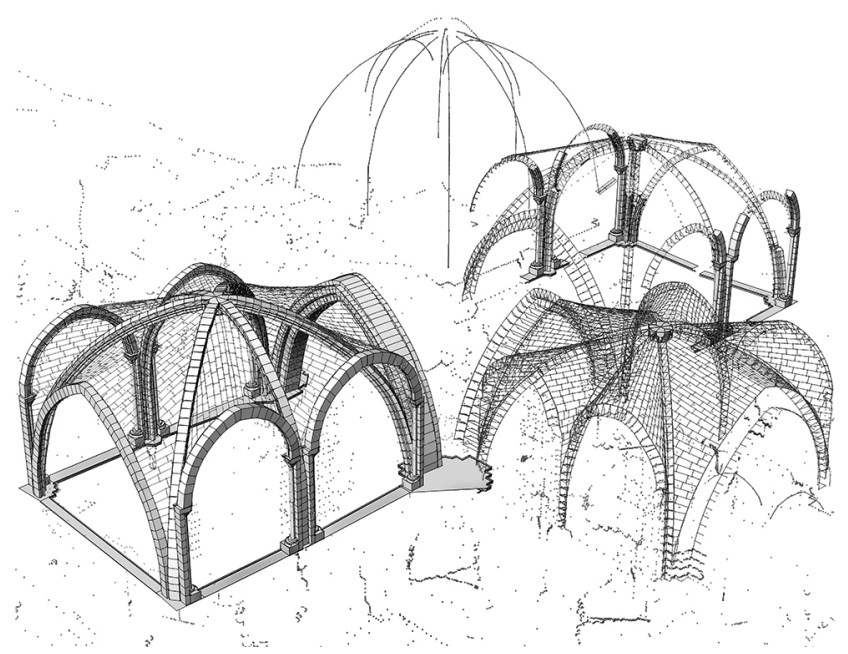

Figura 7. Levantamiento topográfico realizado para analizar las bóvedas de la cabecera. Imagen de la autora.

De esta forma detecté numerosas marcas realizadas por los canteros en la reconstrucción, en forma de "R" de aspecto mecanográfico, que indican qué zonas o elementos se han reconstruido. También encontré la numeración de buena parte de las piezas, fundamentalmente plementos, realizada con pintura, y que sin duda hizo posible el control de las piezas y de su colocación de forma correcta. Este tipo de numeración puede apreciarse en los laterales de las dovelas de los nervios en las fotografías de las bóvedas que Pedro Archilla realizó durante las obras de restauración (11). Ambos tipos de señalización me han permitido definir las zonas reconstruidas frente a las originales, de especial importancia en la bóveda del presbiterio, donde no contamos con una confirmación documental de los procesos de restauración finalmente adoptados.

En el plano de la figura 8 se han señalado las marcas detectadas en la bóveda del presbiterio. Se concentran en su mitad oriental, lo que nos permite confirmar que su mitad Oeste fue finalmente consolidada y es original. Los nervios son casi todos nuevos, con excepcción de las primeras 5 o 6 piezas desde la cornisa, tal y como se aprecia en las fotografías (13). La clave, tal y como indican Torres Balbás y Labrada, es original.

La bóveda del crucero norte fue completamente reconstruida. En ella no se conserva numeración, solo se han encontrado marcas de cantería representando una "R". Esta marca aparece tanto en las dovelas de los nervios como en las plemen- 

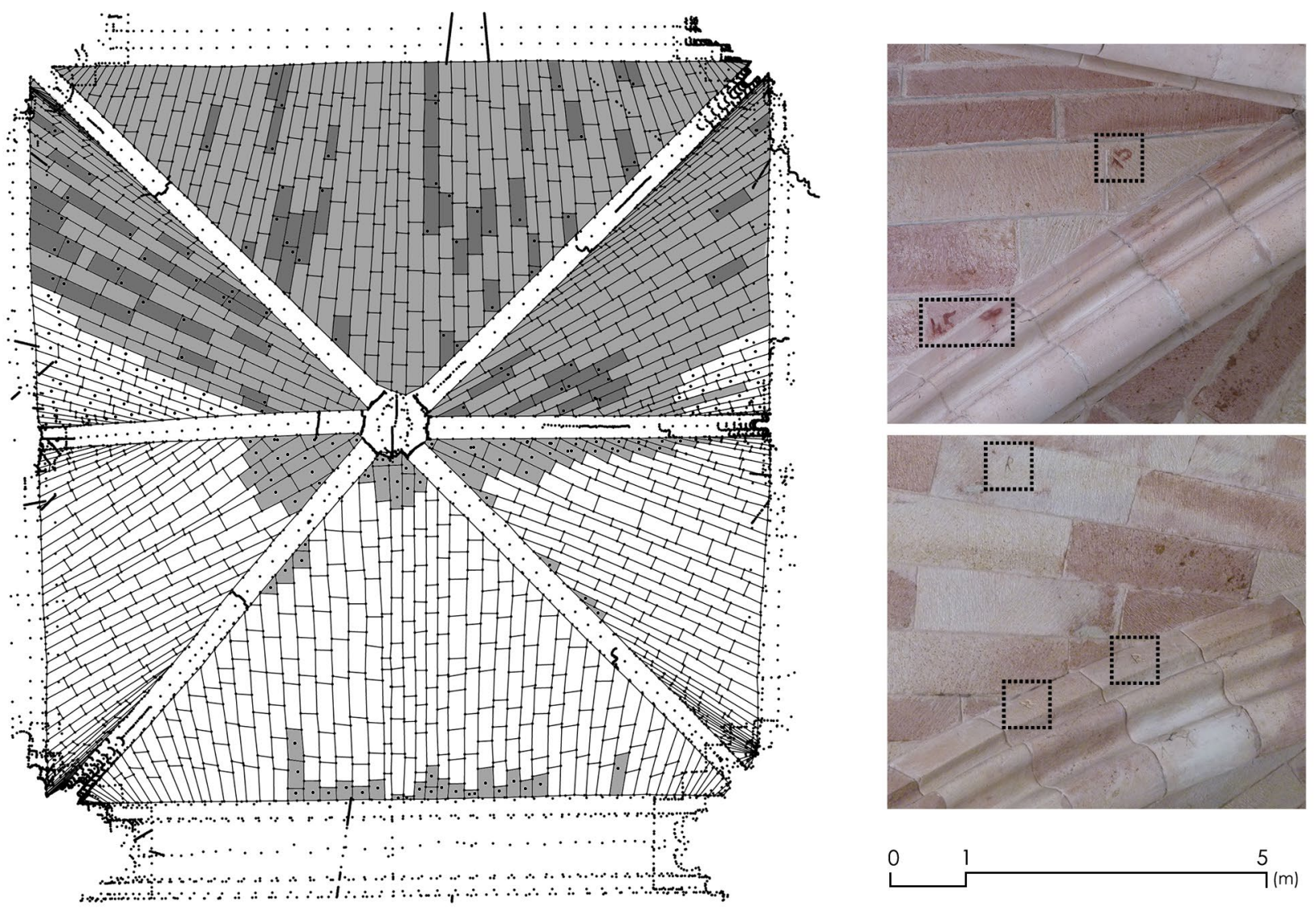

0
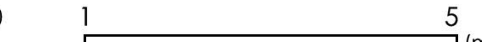

Figura 8. Planta topográfica de la bóveda del presbiterio (izquierda). La parte oscura corresponde a la mitad reconstruida. En color gris claro los plementos de nueva talla, en color gris oscuro los plementos nuevos que conservan las marcas. A la derecha, numeración de las piezas en la bóveda del presbiterio (arriba) y marcas de cantería modernas en la bóveda del crucero norte (abajo). Plano y fotografías de la autora.

terías (figura 8). Solo se conservan originales las dos o tres primeras dovelas de cada nervio. La clave resistió la caída, según afirman ambos arquitectos en sus informes, sin embargo su aspecto es nuevo, por lo que no se ha podido confirmar si se trata de la pieza original restaurada o si por el contrario es una pieza nueva.

Las bóvedas del ábside y del crucero central son completamente nuevas, la primera cuenta con numeración en sus piezas, que aparece en las fotografías de Archilla (figura 6), mientras que la segunda presenta decoración franquista en su clave. La única bóveda original conservada en su totalidad es la del crucero sur.

El cromatismo de la piedra utilizada en los años 40, arenisca con vetas rojizas, permite también diferenciar las zonas reconstruidas frente a las originales (figura 2). La piedra original presenta tonos mucho más pálidos.

\section{DESACUERDOS ENTRE LAS BÓVEDAS ORIGI- NALES Y LAS RECONSTRUIDAS}

El análisis geométrico comparativo de las bóvedas sexpartitas de la cabecera, tanto de las originales como de las reconstruidas, permitió detectar importantes diferencias entre sus monteas. La bóveda original del crucero sigue los parámetros definidos por la tipología representada por la Catedral de París. Su nervio central es semicircular y se peralta aproximadamente 2,70 metros por encima de la línea de cornisa. Los nervios diagonales son semicirculares pero no están peraltados, sus centros están a la altura de la cornisa, tal y como ocurre con los nervios perpiaños, aunque en este caso son arcos apuntados (figura 9). La sobreelevación del nervio de través implica que fueron necesarias dos plataformas de apoyo a distintas alturas para las cimbras, una para la construcción de los nervios diagonales a la altura de la cornisa, a 20 metros del suelo, y la otra 2,70 metros por encima de ésta última, a la cota en la que termina el peralte del nervio central. La forma cupulada de esta bóveda, como la de las bóvedas de la catedral parisina, son propias de las primeras estructuras góticas, con volumetrías características del románico.

La bóveda del crucero norte era igual a la del crucero sur, sin embargo Labrada no debió estudiar a fondo la geometría de la bóveda gemela conservada, donde podían observarse las formas rotundas de los arcos, semicirculares y apuntados. Por el contrario el arquitecto debió situar la altura de la clave central y posteriormente trazó arcos ligeramente apuntados desde los arranques, que conservaban ocho o nueve dovelas originales, llegando a la altura deseada. La bóveda reconstruida presenta nervios diagonales ligeramente apuntados y el nervio central apuntado y peraltado únicamente 2,10 metros sobre la línea de cornisa, el peralte incompleto que marcaban las dovelas conservadas en los arranques. La clave está situada 1,25 metros por encima de su cota original, probablemente como resultado de igualar su altura con la clave de la bóveda sur, lo que provocó que no se pudiese alcanzar su altura con arcos semicirculares (figura 9). 


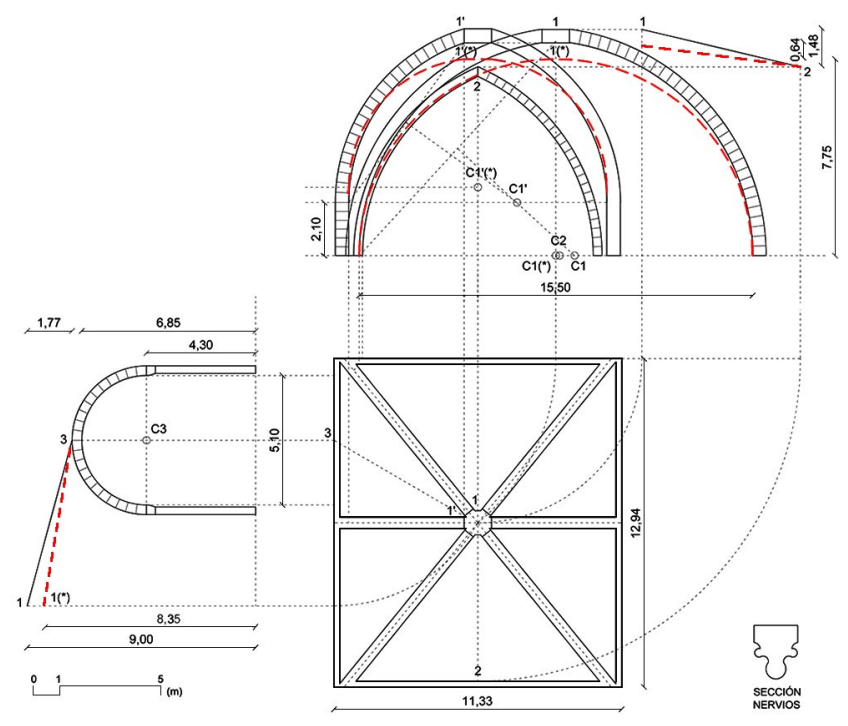

Figura 9. Montea de la bóveda reconstruida del crucero norte con la traza de la montea original en línea discontinua. Dibujo de la autora.

La bóveda del presbiterio debía corresponder a la misma tipología que las de los brazos cruceros, tal y como indica el gran peralte del nervio central que se percibe en las fotografías de la ruina gracias a las dovelas conservadas en los arranques. Las bóvedas sexpartitas cuentan con dos tipologías geométricas principales, o bien el arco central es apuntado y se peralta escasos $30 \mathrm{~cm}$, para emplear la misma curvatura en todos los nervios, o por el contrario se utiliza un arco semicircular, peraltado más de 2 metros y con una curvatura distinta al resto de nervios de la bóveda (2). Las fotografías antiguas nos permiten comprobar que las seis o siete dovelas del arco central que se conservaron se situaban verticales, es decir, formaban parte del peralte, que alcanzaría aproximadamente 2 metros, ya que cada dovela tiene aproximadamente $30 \mathrm{~cm}$ de largo. Estos datos permiten afirmar que la geometría original de este arco era semicircular, y que este peralte permitiría alcanzar la altura de la clave central con esta geometría. Aunque la clave

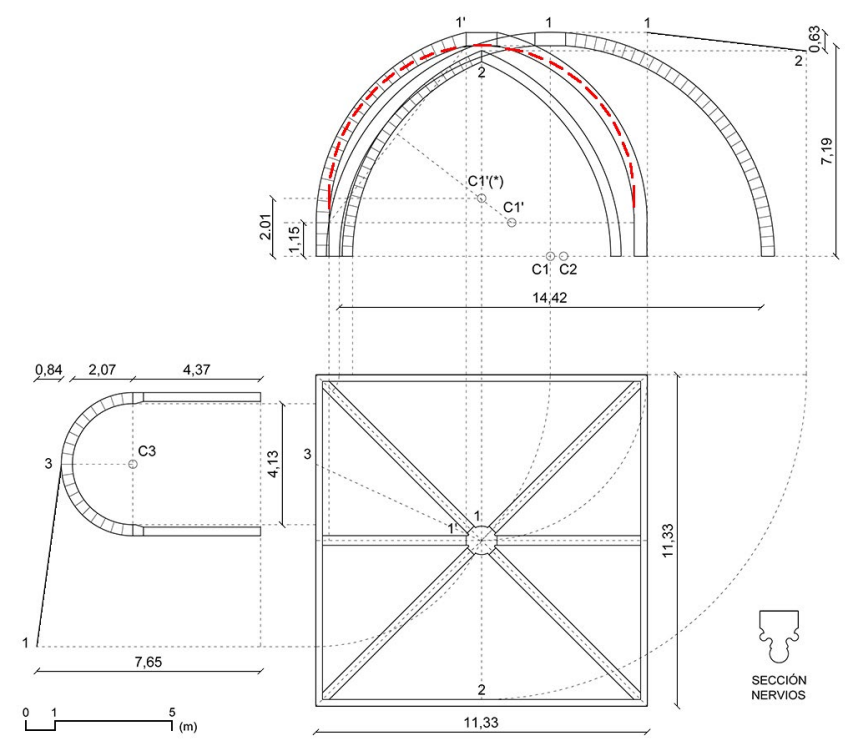

Figura 1o. Montea de la bóveda reconstruida del presbiterio. En línea discontinua la montea original. Dibujo de la autora. se precipitó al suelo, las plementerías que la rodeaban se mantuvieron en pie, lo que permitía conocer su altura. Labrada ignoró estas características geométricas y de nuevo trazó arcos apuntados desde el peralte consolidado, 1,15 metros, que estaba incompleto por lo que la bóveda perdió su geometría original. El resultado es una solución ambigua, a caballo entre las dos tipologías de sexpartita posibles (figura 10).

$\mathrm{Al}$ no haber respetado la geometría medieval, la estandarización entre los distintos nervios existente en la bóveda original no se ha conservado. En la bóveda del crucero sur la curvatura utilizada para definir los nervios diagonales y perpiaños es la misma, lo que permitió simplificar la ejecución de la bóveda y el diseño de los medios auxiliares. Las bóvedas de Labrada se hicieron con curvaturas diferentes para todos los nervios.

El trabajo de cantería fue cuidadoso, ya que las dovelas nuevas se realizaron respetando tanto el perfil de las originales como su longitud, bastante corta, característica del protogótico. La talla de las dovelas no se realizó con baivel sino con escuadra porque se trataba de piezas rectas, sin curvatura, tal y como se labraron en el siglo XIII.

La bóveda del ábside se derrumbó en su totalidad. En las fotografías puede apreciarse que sus dos ventanales situados en la parte norte cayeron por completo, incluyendo los arranques de los nervios de la bóveda y sus apoyos. Sin embargo, los cinco restantes, situados hacia el Este y el Sur, se mantuvieron en pie, conservando los dos orientales las primeras seis y ocho dovelas de sus nervios desde la cornisa. Labrada debió definir la forma de sus nervios teniendo en cuenta la curvatura de los arranques que aún estaban en pie, describiendo arcos apuntados hasta alcanzar la altura de la clave, siguiendo el mismo criterio que en la bóveda del crucero Norte. La posición de la clave original, perdida en el derrumbe, podía determinarse al ser conocida su situación en planta y la forma apuntada de sus nervios.

\section{LA INVENCIÓN DE LA BÓVEDA DEL CRUCERO CENTRAL}

No se conoce la morfología de la bóveda del crucero central original, que fue levantada junto con las dos bóvedas sexpartitas del brazo transepto en el siglo XIII. Muñóz Párraga opina que se habría cerrado con otra bóveda sexpartita (20), aunque es extraño encontrar esta tipología en los cruceros centrales, donde si es más habitual el uso de octopartitas, como en la Catedral de Laon, con dos nervios formeros por cada uno de los cuatro lados de la bóveda. En el siglo XV el Cardenal Mendoza sustituyó la bóveda protogótica del crucero por la bóveda cuatripartita que se destruyó en la Guerra Civil, tratando de solucionar los problemas de estabilidad que presentaba la estructura. El derrumbe de la bóveda de Mendoza permitió descubrir los fustes de apoyo de la bóveda original en las cuatro esquinas, tal y como menciona Torres Balbás en sus informes. Estos fustes se pueden ver en las fotografías conservadas (figura 12). Fueron comunes en las bóvedas octopartitas que se elevaban sobre el crucero para introducir luz en la iglesia a través del cimborrio. Sin embargo solo se conservan los de las esquinas, y las octopartitas requieren otros cuatro fustes añadidos, uno en el centro de cada lienzo de apoyo para dar respuesta a los soportes entre los dobles formeros. La ausencia de fustes centrales podría indicar que la bóveda protogótica no era octopartita, sino cuatripartita, elevada a una cota bastante más alta que la bóveda de Mendoza. 
En el proyecto de 1942, Labrada plantea la solución a adoptar para la reconstrucción de la bóveda del crucero, que tuvo que detenerse a mitad de su ejecución por agotarse el presupuesto (17). Se plantea la posibilidad de rehacer la supuesta solución original de la bóveda protogótica o por el contrario rehacer la bóveda cuatripartita del Cardenal Mendoza a partir de los arranques conservados. En el proyecto se declina por la realización de una bóveda sexpartita apoyada sobre la cornisa original, siguiendo el diseño del resto de sexpartitas de la catedral, solución que justifica para devolver la antigua silueta exterior al edificio. Sin embargo Labrada cambió la solución durante las obras, optando por una bóveda octopartita (figura 11), similar a la de la Catedral de Laon. En todo caso se trata de una hipótesis sobre la morfología de la bóveda original del siglo XIII que no puede ser confirmada.

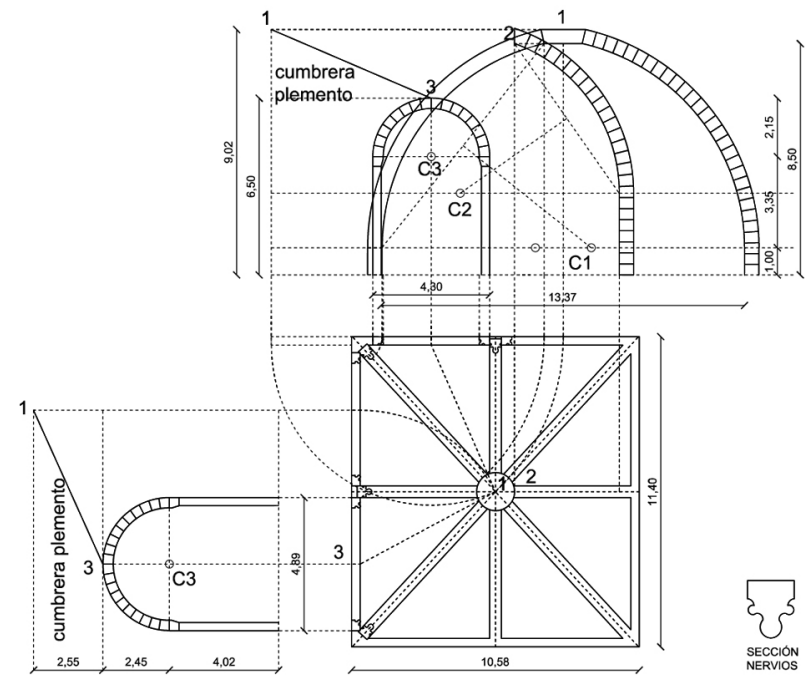

Figura 11. Montea de la bóveda octopartita del crucero central construida por Antonio Labrada. Dibujo de la autora.

La bóveda octopartita de Labrada, a menudo mal representada con arcos rebajados (22), es una bóveda muy estilizada, con arcos apuntados que permiten una elevación añadida a la del cuerpo del crucero sobre el que se levanta, alcanzando su clave los 36,62 metros de altura (figura 12). El diseño de la escultura de sus elementos indica su factura en plena postguerra, tal y como señala el escudo franquista en la tortera de la clave, lo que permite distinguir esta parte de la reconstrucción a simple vista.

\section{CONCLUSIONES}

La falta de documentación técnica una vez terminadas las obras de restauración en la Catedral de Sigüenza no hacía posible la distinción entre las partes originales y las reconstruidas. En algunas zonas de la estructura, como la bóveda del presbiterio, cuya mitad occidental resistió los bombardeos aunque presentaba serios daños, no era posible conocer si se había reconstruido en su totalidad o se habían consolidado las fábricas originales. Los investigadores que han estudiado la catedral hasta la fecha la consideraban completamente reconstruida.

El estudio pormenorizado de estas bóvedas a partir de la medición con estación total láser me ha permitido detectar y señalar las marcas en las piezas reproducidas a partir del perfil de las dovelas originales y la numeracion utilizada por Antonio Labrada para organizar la colocación de dovelas y plementos. De esta forma se han podido determinar las zonas reconstruidas, pudiendo concluir que la mitad occidental de la boveda del presbiterio fue consolidada y es original.

Por otro lado la comparacion de la geometría y construccion de las bovedas reconstruidas frente a la boveda original del crucero sur, me ha permitido concluir que las bóvedas se rehicieron sin apoyarse en estudios previos. No se utilizaron las geometrías propias de esta tipología, caracteristica importante ya que las asocia con la Catedral de Notre Dame de París y permite establecer el área de influencia de la catedral en la Edad Media, que conecta el edificio protogótico con la Île de France y el sur de la región de la Picardía francesa. Las geometrías utilizadas por Labrada son ambiguas y confusas, lo que indica que el conocimiento de los procedimientos constructivos medievales era todavía muy limitado en la postguerra.

A pesar de los desacuerdos con las bovedas originales, la reconstruccion de Sigüenza resulta un buen ejemplo, donde los medios disponibles dificultaron enormemente las obras pero los criterios de restauracion permitieron devolver el esplendor a la catedral, con ciertas dudas sobre la invención de la boveda del crucero, que sin embargo permitió una mayor entrada de luz en el edificio, ya de por sí oscuro.
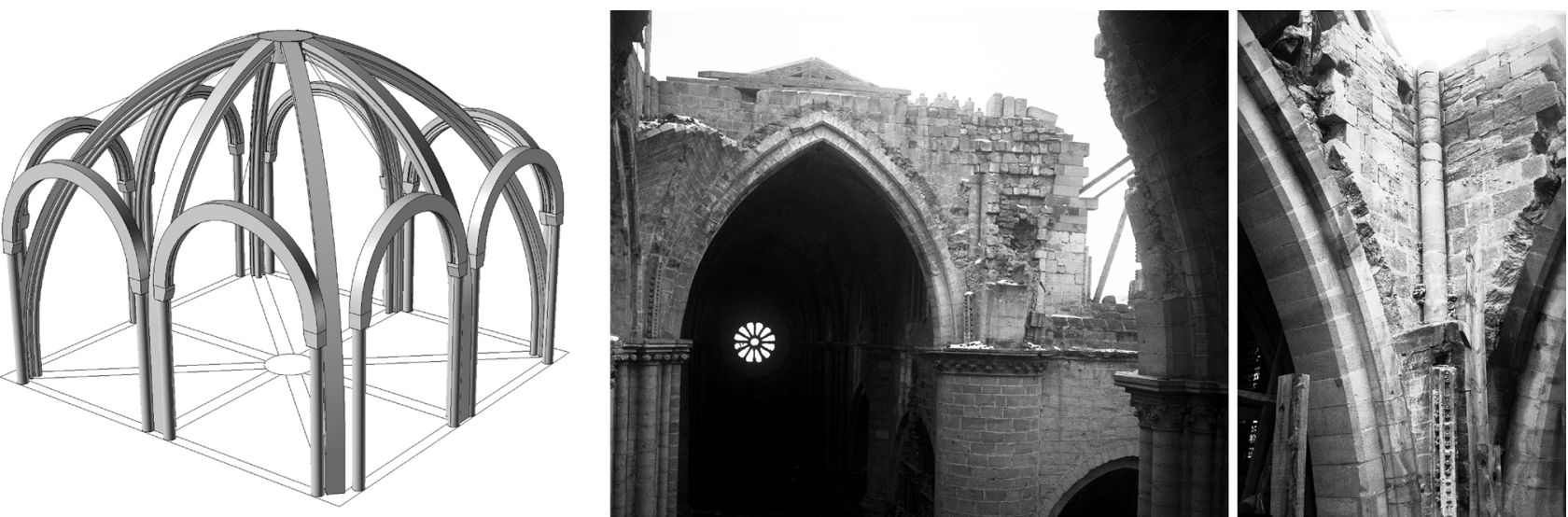

Figura 12: Izquierda: Modelo $3 \mathrm{D}$ de la bóveda octopartita construida por Labrada en el crucero. Figura realizada por la autora a partir de la medición topográfica llevada a cabo en la cabecera. Derecha: Fustes ocultos tras la ruina de la bóveda cuatripartita del Cardenal Mendoza construida en el siglo XV en el crucero central. Fotografías de Pedro Archilla Salido, 1941 (11). 


\section{AGRADECIMIENTOS}

Mi agradecimiento al Cabildo de la Catedral de Sigüenza que me facilitó la campaña de medición permitiéndome pasar in- numerables horas observando sus bóvedas entre mayo y septiembre de 2011. Gracias también a José Juste Ballesta por facilitarme las fotografías y los planos de los archivos consultados.

\section{REFERENCIAS / REFERENCES}

(1) Maira Vidal, R. (2018). Abandonment of sexpartite vaults: construction difficulties and evolution. En I. Wouters, S. Van de Voorde e I. Bertels (Eds.), Building Knowledge, Constructing Histories Vol. II (879-886). Leiden: CRC Press. Taylor and Francis Group.

(2) Maira Vidal, R. (2017). The evolution of the knowledge of geometry in Early Gothic construction: the development of the sexpartite vault in Europe. International Journal of Architectural Heritage, vol. 11, 7, 1005-1025. https://doi.org/ 10.1080/15583058.2017.1332254

(3) Maira Vidal, R. (2021). Geometry and construction of the severies of the vaults in the Cathedral of Notre Dame de Paris. En J. Mascarenhas-Mateus e A. P. Pires (Eds.), History of Construction Cultures, Vol. II (341-348). Leiden: CRC Press. Taylor and Francis Group. DOI: https://doi.org/10.1201/9781003173434.

(4) Torres Balbás, L. (23 de enero 1941). Escrito de respuesta del arquitecto Torres Balbás al Oficio de Ministerio de Gobernación con fecha 8 de Enero de 1941. Archivo General de la Administración (AGA).

(5) Torres Balbás. L. (31 de julio 1940) Memoria del $2^{\circ}$ Proyecto de Restauración de la Catedral de Sigüenza. Junta Técnica de Estado. Archivo General de la Administración (AGA).

(6) Torres Balbás. L. (1939). Las teorías sobre la arquitectura gótica y las bóvedas de ojivas. Las ciencias 4, $223-233$.

(7) Torres Balbás. L. 1945. Función de nervios y ojivas en la arquitectura gótica. Investigación y progreso, 6-7, 214-231.

(8) Viollet Le Duc. E. E. (1996). La construcción medieval. Madrid: Instituto Juan de Herrera.

(9) Gilman, R. (1920). The Theory of Gothic Architecture and the Effect of Shellfire at Reims and Soissons. American Joumal of Archeology, vol. 24, 1, 37-74.

(10) Labrada Chércoles. A. (31 de diciembre 1940) Informe sobre el estado de las obras. Ministerio de Gobernación. Archivo General de la Administración (AGA).

(11) Archilla Salido, P. Archivo fotográfico de la Catedral de Sigüenza desde 1891 a 1950. Ministerio de Educación, Cultura y Deporte (2013). Consulta en: http://iris.cnice.mec.es/coleccion/Pedroarchilla/.

(12) Torres Balbás, L. (5 de agosto 1940). Planos complementarios del Proyecto de Restauración de la Catedral de Sigüenza. Junta Técnica de Estado. Archivo General de la Administración (AGA).

(13) Labrada Chércoles. A. Archivo fotográfico de la destrucción de la Catedral de Sigüenza entre 1940 y 1950. Consulta en el Archivo General de la Administración (AGA), en el Archivo de la Catedral de Sigüenza, en el Archivo del Instituto del Patrimonio Histórico Español del Ministerio de Educación, Cultura y Deporte y en la revista Reconstrucción. Dirección General de Regiones Devastadas y Reparaciones, números 11, 12, 22, 24.

(14) Fitchen, J. (1981). The Construction of Gothic Cathedrals. A Study of Medieval Vault Erection. Chicago: The University of Chicago Press.

(15) Maira Vidal, R. (2016). Sistemas auxiliares para la construcción de las bóvedas europeas en el gótico primitivo: características y evolución. En R. Fernandes Póvoas y J. Mascarenhas Mateus (Eds.), Actas del II Congresso Internacional de História da Construçáo Luso-Brasileira. Culturas Partilhadas Vol. II (pp. 855-866). Porto: Centro de estudos de Arquitectura e Urbanismo. Facultade de Arquitectura de la Universidade de Porto.

(16) Labrada Chércoles, A. (7 de septiembre 1943). Planos del Proyecto de Restauración de la Catedral de Sigüenza ( ${ }^{\mathrm{a}}$ fase). Ministerio de la Gobernación. Archivo General de la Administración (AGA).

(17) Labrada Chércoles, A. (7 de septiembre 1943). Memoria del Proyecto Reformado al de Restauración de la Catedral de Sigüenza ( $2^{\mathrm{a}}$ fase). Ministerio de la Gobernación. Archivo General de la Administración (AGA).

(18) Labrada Chércoles, A. (1942) La Catedral de Sigüenza. Reconstrucción. Dirección General de Regiones Devastadas y Reparaciones, 22, 153-160.

(19) Juste Ballesta, J. (2007). Transformación y Restitución de la Catedral de Sigüenza y su entorno urbano (Tesis doctoral). Universidad Politécnica de Madrid.

(20) Muñoz Párraga, M.C. (1987). La Catedral de Sigüenza (Las fábricas románica y gótica). Guadalajara: Publicaciones del Cabildo de la S.I.C.B. de Sigüenza.

(21) Maira Vidal, R. (2015). Bóvedas sexpartitas. Los orígenes del gótico (Tesis doctoral no publicada). Universidad Politécnica de Madrid. http://oa.upm.es/40989/.

(22) Juste Ballesta, J., Barceló de Torres, E. (2006). La Catedral de Sigüenza, la puesta en práctica de un plan director. Madrid: Lunwerg Editores. 